\title{
Estimating Location Accuracy of Stationary Emitter in Presence of Biasing in Receiver Position and Velocity by Exploiting Cross Ambiguity Function
}

\author{
Anupam Sharma, Suman Agrawal, Charul Bhatnagar, D. S. Chauhan
}

\begin{abstract}
This paper proposes CAF algorithm to estimate localisation accuracy of a stationary emitter which is being monitored by a pair of sensors mounted on high altitudes. It computes joint Time Difference of Arrival (TDOA) and Frequency Difference of Arrival (FDOA) using Cross Ambiguity Function (CAF) and measures geolocation accuracy in presence of biasing in sensor position and velocity. Previous work in this area utilizes TDOA and FDOA measurements with known sensor kinematics which is fed to Maximum Likelihood or Least Squares algorithm for post processing. However it is computation demanding. In the present work, surface peaks of TDOA and FDOA values are directly mapped to geographic coordinates. This method is computationally efficient. As sensor and emitter geometry keeps changing over time due to moving sensors, multiple CAF snapshots are taken for emitter geolocation. Simulations are carried out using MATLAB. It is observed that at $30 \mathrm{~dB}$ SNR, location accuracy of stationary emitter is $100 \mathrm{~m}$ at known sensor kinematics and by introducing bias in the receiver position and velocity, it is $\mathbf{2 0 0}$ meters. These measurements are well within and in accordance with theoretical developments.
\end{abstract}

Keywords: Cross Ambiguity Function, Frequency Difference of Arrival, Localisation, Time Difference of Arrival, Unmanned Aerial Vehicle.

\section{INTRODUCTION}

Estimating precise geographical location of a stationary emitter is critical for both military and civilian applications. Received Signal Strengths (RSS), Time Of Arrival (TOA), Time Difference Of Arrival (TDOA) and Angle Of Arrival (AOA) are some of the techniques used for localisation, each with its associated strengths and weakness. However, localisation using joint TDOA and FDOA measures is quite popular Classical methods of localisations based on TDOA and FDOA was a two-step process. In the first step, differential delay and Doppler frequency shifts between pair of sensor is measured In the second step, these estimates are used in statistical signal processing algorithms for emitter location But these methods were computationally too extensive and gave accurate results only in special conditions.

Revised Manuscript Received on February 05, 2020.

* Correspondence Author

Anupam Sharma*, Defence Electronics Research Laboratory, DRDO, Hyderabad, India. E-mail: anupamsharma117@yahoo.com

Suman Agrawal, Defence Electronics Research Laboratory, DRDO, Hyderabad, India. E-mail: suman02@gmail.com

Prof.Charul Bhatnagar, Professor in the Department of Computer Engineering and Applications, GLA University, Mathura, India. E-mail: charul@gla.ac,in

Prof. D. S. Chauhan, Pro-Chancellor, GLA University, Mathura, India. E-mail: pdschauhan@gmail.com

(c) The Authors. Published by Blue Eyes Intelligence Engineering and Sciences Publication (BEIESP). This is an open access article under the CC BY-NC-ND license (http://creativecommons.org/licenses/by-nc-nd/4.0/)
Conventional TDOA and FDOA methods based on CAF using higher order statistics, wideband signals and uncorrelated signals is also covered in literature Also the problem of joint TDOA and FDOA is studied in widely. But these methods required large amount of data to be shared between sensors before doing CAF measurements. In this work we consider the use of joint TDOA and FDOA using CAF-map measurements along with moving target model, in order to estimate the stationary emitter placed on the surface of the earth. Measurements using TDOA only requires minimum of three sensors corresponding to two TDOA measurements and intersection of two hyperbolas. FDOA only measurement can happen when there is a Doppler shift. CAF has an advantage as it uses joint TDOA and FDOA measurement. It is also attractive as it requires minimal number of sensors (two UAVs) which is easy to be deployed. In CAF-map method the estimated TDOA and FDOA measurements are mapped on the earth surface. Then the emitter location is estimated from this map which maximises the magnitudes of the CAF map.

The main contributions of this paper are as follows:

1. The proposed paper estimates geolocation accuracy of RF emitters using moving sensors placed on mobile platform / high altitudes.

2. Cross ambiguity function is used to compute surface peaks of TDOA and FDOA measurements. These are then mapped directly to geographical coordinates.

3. Geolocation accuracy is computed in presence of bias in sensor kinematics. Results are tabulated for the same.

4. Simulations are carried out using MATLAB toolbox. Using the proposed method, better geolocation accuracy is achieved with less complexity.

The remainder of this paper is organised as follows: In section II, joint TDOA and FDOA localisation model is introduced. Properties of two dimensional Cross Ambiguity Function and its algorithm is formulated in section III. Simulations and results of proposed algorithm is covered in section IV. Conclusions and future directions of this work is given in section $\mathrm{V}$.

\section{JOINT TDOA AND FDOA LOCALISATION MODEL}

In this section we'll discuss the localisation scenario and formulate the problem statement mathematically.

\section{A. Problem Formulation}

For localisation scenario, the following assumptions are made. It is assumed that emitter is fixed and placed on the surface of the earth. 


\section{Estimating Location Accuracy of Stationary Emitter in Presence of Biasing in Receiver Position and Velocity by Exploiting Cross Ambiguity Function}

Signals are received at the emitter using pair of sensors which are either mobile or airborne (preferably Unmanned Aerial Vehicles (UAVs)). Also for the passive emitter localisation system it is assumed that there is Line of sight between the transmitting emitter and a pair of receivers. For sake of simplicity, multipath is assumed to be negligible. An example of such a scenario would be localisation of a stationary transponder placed on surface of earth which is being steered by a pair of receivers which are placed on mobile platform. These assumptions do not affect the emitter localisation accuracy.

Assume position of the emitter is $\mathbf{p}^{\mathrm{e}}(\mathrm{t})=\left[\mathrm{x}_{\mathrm{t}}^{\mathrm{e}}, \mathrm{y}_{\mathrm{t}}^{\mathrm{e}}, \mathrm{z}_{\mathrm{t}}^{\mathrm{e}}\right]^{\mathrm{T}} \in \mathbb{R}^{3 \times 1}, \mathrm{~T}$ denotes the matrix transpose. This emitter position is estimated through $M$ receivers, $M=2$, which measures signals emitted by emitter. Let us represent the position of receiver by $\mathbf{p}^{\circ}=\left[\mathbf{p}_{1}^{\circ \mathrm{T}}, \mathbf{p}_{2}^{\mathrm{oT}}\right]^{\mathrm{T}}$ and its velocity by $\dot{\mathbf{p}}^{\circ}=\left[\dot{\mathbf{p}}_{1}^{\circ \mathrm{T}}, \dot{\mathbf{p}}_{2}^{\circ \mathrm{T}}\right]^{\mathrm{T}}$, where $\mathbf{p}_{\mathrm{j}}^{\circ}$ and $\dot{\mathbf{p}}_{\mathrm{j}}^{\circ}$ are the location parameters of receiver $\mathrm{j}, \mathrm{j}=1$, 2. In Cartesian coordinate, $\mathbf{p}_{\mathrm{j}}^{\circ}(\mathrm{t})=\left[\mathrm{x}_{\mathrm{t}}^{\circ}, \mathrm{y}_{\mathrm{t}}^{\circ}, \mathrm{z}_{\mathrm{t}}^{\circ}\right]^{\mathrm{T}} \in \mathbb{R}^{3 \times 1}, \mathrm{j}=1,2$ denotes the position vector of receiver, and corresponding velocity vector is $\dot{\mathbf{p}}_{\mathrm{j}}(\mathrm{t})$. In this paper we'll consider two cases. Firstly $\mathbf{p}^{\circ}$ and $\dot{\mathbf{p}}^{\circ}$ are known and $\mathbf{p}^{\mathrm{e}}(\mathrm{t})$ has to be localised accurately. In the second case, exact $\mathbf{p}^{\circ}$ and $\dot{\mathbf{p}}^{\circ}$ is not known and biasing is introduced i.e. $\quad \mathbf{p}=\left[\mathbf{p}_{1}^{\mathrm{T}}, \mathbf{p}_{2}^{\mathrm{T}}\right]^{\mathrm{T}}=\mathbf{p}^{\circ}+\Delta \mathbf{p} \quad$ and $\dot{\mathbf{p}}=\left[\dot{\mathbf{p}}_{1}^{\mathrm{T}}, \dot{\mathbf{p}}_{2}^{\mathrm{T}}\right]=\dot{\mathbf{p}}^{\circ}+\Delta \dot{\mathbf{p}}$, where $\Delta \mathbf{p}_{\mathrm{j}}$ and $\Delta \dot{\mathbf{p}}_{\mathrm{j}}$ are the bias in the receiver position and also in receiver velocity. In vector form, the receiver location is denoted by $\boldsymbol{\beta}=\left[\mathbf{p}^{\mathrm{T}}, \dot{\mathbf{p}}^{\mathrm{T}}\right]^{\mathrm{T}}=\boldsymbol{\beta}^{\circ}+\Delta \boldsymbol{\beta}$. Here $\Delta \boldsymbol{\beta}=\left[\Delta \mathbf{p}^{\mathrm{T}}, \Delta \dot{\mathbf{p}}^{\mathrm{T}}\right]^{\mathrm{T}}$ is assumed to be a vector of random, zero mean of Additive White Gaussian Noise (AWGN). In the presence of biasing, again the location accuracy of $\mathbf{p}^{\mathrm{e}}(\mathrm{t})$ will be determined. The objective of this paper is to estimate $\mathbf{p}^{\mathrm{e}}(\mathrm{t})$ as accurately as possible under no bias and bias conditions.

\section{TWO-DIMENSIONAL CROSS AMBIGUITY FUNCTION}

Consider a stationary emitter transmitting a narrowband signal $s(t)$ whose carrier frequency is $f_{c}$. Bandwidth of signal $\mathrm{s}(\mathrm{t})$ is $\mathrm{B}$ and it satisfies the condition $\mathrm{B} \ll \mathrm{f}_{\mathrm{c}}$. This signal can be modelled as $\mathrm{s}(\mathrm{t}) \mathrm{e}^{\mathrm{j} 2 \pi \mathrm{f}_{\mathrm{c}} \mathrm{t}}$. This signal is observed by a pair of moving receivers and it becomes $\mathrm{s}(\alpha \mathrm{t}) \mathrm{e}^{\mathrm{j} 2 \pi \mathrm{f}_{\mathrm{c}} \alpha \mathrm{t}}$ which causes Doppler shift. This signal can be approximated as $\mathrm{s}(\mathrm{t}) \mathrm{e}^{\mathrm{j} 2 \pi \mathrm{f}_{\mathrm{c}} \alpha \mathrm{t}}$. As distance between emitter and receiver exists, the signal will be delayed by $\tau$ and the signal becomes $\mathrm{s}(\mathrm{t}-\tau) \mathrm{e}^{\mathrm{j} 2 \pi \mathrm{f}_{\mathrm{c}} \alpha \mathrm{t}}$. Even though signal source is common to both UAVs, there is a time difference of arrival caused due to different paths travelled by the signal and Doppler frequency shift as both the receivers are moving with different velocities. For jointly estimating TDOA and FDOA measurements, Cross Ambiguity Function (CAF) is calculated. This function correlates the signals $s_{1}(t)$ and $s_{2}(t)$ which is received by receivers 1 and 2 . These signals are parameterised by time lag $\tau$ and Doppler shift $v$. Mathematically it can be written as

$$
\begin{aligned}
& s_{1}(t)=s(t)+n_{1}(t) \\
& s_{2}(t)=s(t-v) e^{j f(t-\tau)}+n_{2}(t)
\end{aligned}
$$

where, $s_{1}(t)$ is the signal received at $U_{A} V_{1}$ with AWGN as $\mathrm{n}_{1}(\mathrm{t})$ at $\mathrm{s}(\mathrm{t}) . \mathrm{s}_{2}(\mathrm{t})$ is the signal received at $\mathrm{UAV}_{2}$ with AWGN $\mathrm{n}_{2}(\mathrm{t})$. It is added with time delay $\tau$ and frequency difference $v$ to the signal $\mathrm{s}(\mathrm{t})$. The CAF is defined as

$$
A(\tau, v)=\int_{0}^{T} S_{1}(t) s_{2}^{*}(t+\tau) e^{-j 2 \pi v t} d t
$$

In which $T$ represents the integration time, * is conjuction , $j=\sqrt{-1}$ denotes imaginary part. Writing in discrete form, this equation can be written as

$$
A(\tau, k)=\sum_{n=0}^{N-1}\left[s_{1}(n) s_{2}^{*}(n-\tau)\right] e^{-j 2 \pi \frac{k n}{N}}
$$

where, $\mathrm{t}=\mathrm{nTs}, v=\frac{k f_{s}}{N}, T_{s}=$ Sampling period, $f_{s}=\frac{1}{T_{s}}$ represents sampling frequency, $n$ represents sample numbers and $N$ as total number of samples.

Estimates of TDOA and FDOA measurements are found by optimising the following

$$
\left\{\hat{\tau}_{\mathrm{m}}, \hat{v}_{\mathrm{m}}\right\}=\arg _{\tau, v} \max |\mathrm{A}(\tau, v)|
$$

where, $A(\tau, v)$ is the CAF.

\section{A. CAF Map Algorithm}

For the received signals $\mathrm{s}_{1}(\mathrm{t})$ and $\mathrm{s}_{2}(\mathrm{t})$, TDOA and FDOA estimates are calculated theoretically. Then a lookup table is created for the calculated theoretical values. Joint TDOA and FDOA measurements are taken using CAF. CAF map algorithm directly maps the theoretical values to a common geographic frame. Considering the search area as grid and emitter to be located as placed on grid, CAF is evaluated on the grids of time grid and frequency grid using grid search. During this, the time resolution is $T_{s}$ and frequency resolution is $\frac{1}{\mathrm{~T}_{\mathrm{s}}}$. For the maximum value of CAF, the time bin and the frequency bin is found out. Main lobe is searched for and then the maximisation is done.

Algorithm for joint TDOA and FDOA using CAF considering no-bias in sensor kinematics is summarized in Algorithm 1. The same procedure is repeated by introducing bias in the sensor / receiver position and velocities. Algorithm for joint TDOA and FDOA using CAF considering bias in sensor kinematics is summarized in Algorithm 2. 
Algorithm 1. CAF Map algorithm without bias

\section{Algorithm 1. CAF Map algorithm with no-bias in sensor kinematics}

\footnotetext{
Input:

1) Enter initial position vector of sensor 1 as $\left\{\mathbf{p}_{1}^{\circ}\right\}$

2) Enter initial position vector of sensor 2 as $\left\{\mathbf{p}_{2}^{\circ}\right\}$

3) Enter initial velocity vector of sensor 1 as $\left\{\dot{\mathbf{p}}_{1}^{\circ}\right\}$

4) Enter initial position vector of sensor 2 as $\left\{\dot{\mathbf{p}}_{2}^{\circ}\right\}$

5) Signal generated from emitter is $s(t)$

6) Define area of interest for the emitter

7) Define the grid sizes.

8) for $m=1$ to number of snapshots

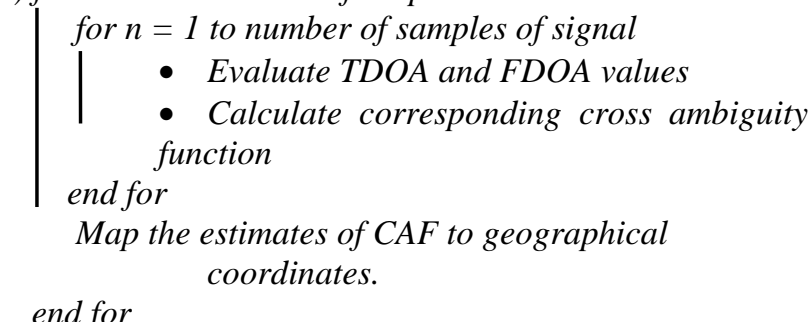

6) Find the CAF peaks from defined grid values on area of interest.

\section{Output:}

7) Estimated CAF peak values

8) 3D CAF plot showing estimated geolocation accuracy.
}

\section{Algorithm 2. CAF Map algorithm with bias}

Algorithm 2. CAF Map algorithm with bias in sensor kinematics.

\section{Input:}

1) Enter initial position vector of sensor 1 as $\left\{\mathbf{p}_{1}^{\circ}\right\}$

2) Enter initial position vector of sensor 2 as $\left\{\mathbf{p}_{2}^{\circ}\right\}$

3) Enter initial velocity vector of sensor 1 as $\left\{\dot{\mathbf{p}}_{1}^{\circ}\right\}$

4) Enter initial position vector of sensor 2 as $\left\{\dot{\mathbf{p}}_{2}^{\circ}\right\}$

5) Add random bias in position vector of sensor 1 . $\Delta \mathbf{p}_{1}=\mathbf{p}_{1}^{\circ}+\sigma_{1}$

6) Add random bias in position vector of sensor 2. $\Delta \mathbf{p}_{2}=\mathbf{p}_{2}^{\circ}+\sigma_{2}$

7) Add random bias in velocity vector of sensor 1 . $\Delta \dot{\mathbf{p}}_{1}=\dot{\mathbf{p}}_{1}^{\circ}+\sigma_{1}$

8) Add random bias in velocity vector of sensor 2. $\Delta \dot{\mathbf{p}}_{2}=\dot{\mathbf{p}}_{2}+\sigma_{2}$

9) Signal generated from emitter is $s(t)$

10) Define area of interest for the emitter

11) Define the grid sizes.

12) for $m=1$ to number of snapshots for $n=1$ to number of samples of signal

- Evaluate TDOA and FDOA values

- Calculate corresponding cross ambiguity function

end for

Map the estimates of CAF to geographical coordinates.

end for

13) Find the CAF peaks from defined grid values on area of interest.

Retrieval Number: C4738029320/2020@BEIESP

DOI: 10.35940/ijeat.C4738.029320

Journal Website: www.ijeat.org
Output:

14) Estimated CAF peak values

15) $3 D$ CAF plot showing estimated geolocation accuracy.

\section{SIMULATION RESULTS}

This section contains quantitative results to demonstrate the proposed algorithm and evaluate it under no bias and bias conditions. The initial position and velocity of a pair of UAVs / receivers considered is $\mathbf{p}_{1}^{\circ \mathrm{T}}=[0,2,8] \mathrm{km}$ and $\dot{\mathbf{p}}_{1}^{\circ \mathrm{T}}=[100,0,0] \mathrm{m} / \mathrm{sec} \quad \mathbf{p}_{2}^{\circ \mathrm{T}}=[3,0,8] \mathrm{km} \quad$ and $\dot{\mathbf{p}}_{2}^{\mathrm{T}}=[100,0,0] \mathrm{m} / \mathrm{sec}$ respectively. The true position and velocity of the stationary emitter is $(11,11,0) \mathrm{km}$ and $(0,0,0)$ $\mathrm{m} / \mathrm{sec}$. For computer simulations, we have assumed binary signal with signal parameters as listed in Table- I.

Table- I: Input parameters used during simulation

\begin{tabular}{|l|l|}
\hline $\begin{array}{l}\text { Input System } \\
\text { Parameters }\end{array}$ & Value \\
\hline Input Carrier Frequency & $\mathrm{fc}=1000.025 \mathrm{MHz}$ \\
\hline $\begin{array}{l}\text { Input Sampling } \\
\text { Frequency }\end{array}$ & $\mathrm{fs}=100 \mathrm{KHz}$ \\
\hline Symbol rate & $10,000 \mathrm{symbols} / \mathrm{sec}$ \\
\hline Signal to Noise Ratio & $\mathrm{S} 1=30 \mathrm{~dB}, \mathrm{~S} 2=30 \mathrm{~dB}$ \\
\hline Number of samples & $\begin{array}{l}\text { variable }\left(\mathrm{N}=2^{13}, 2^{14},\right. \\
\left.2^{16}\right)\end{array}$ \\
\hline Number of snapshots & $10,20,30$ \\
\hline
\end{tabular}

For varying emitter receiver geometry is over time, various snapshots of the signal is taken. Here we have considered signal length corresponding to number of samples of signal taken as $2^{13}=8192,2^{14}=16384$ and $2^{16}=65536$. Also number of snapshots taken is 10, 20 and 30. For each snapshot the code is run for $\mathrm{N}$ times and results are tabulated.

\section{A. Case 1: No bias in Sensor Kinematics}

Under no bias conditions and with the initial position and velocity of receivers as mentioned, emitter localisation is evaluated. Results is shown in Table II for 10 snapshots, Table III for 20 snapshots and Table IV for 30 snapshots, all at varying signal lengths.

It is observed that at a given snapshot and varying the number of samples $(\mathrm{N})$ for each increment of snapshot, output emitter location as well as localisation accuracy (in metres) increases. By increasing the number of snapshots also for corresponding signal lengths $\mathrm{N}$, the output emitter location as well as localisation accuracy increases. Accuracy of $100 \mathrm{~m}$ is obtained for $2^{16}$ samples and at 30 snapshots. Simulations were not carried beyond the signal length of $2^{16}$ as it was time consuming. Three dimensional (3D) CAF-map for signal lengths $\mathrm{N}=2^{13}, 2^{14}$ and $2^{16}$ each at 30 snapshots is shown in Figs. 1, 2 and 3 respectively. Here $\mathrm{x}$-axis, $\mathrm{y}$-axis represent the output emitter location coordinates and $\mathrm{z}$-axis represents the CAF peak value. As apparent from these figures, at higher number of samples $\left(2^{16}\right)$ and 30 snapshots, CAF peak is higher and more sharp with less side lobes and less noise floor indicating greater geolocation accuracy.

Published By:

Blue Eyes Intelligence Engineering

\& Sciences Publication 
Estimating Location Accuracy of Stationary Emitter in Presence of Biasing in Receiver Position and Velocity by Exploiting Cross Ambiguity Function

Table- II. Estimated Emitter Location under no bias in sensor kinematics at 10 snapshots

\begin{tabular}{|c|c|c|c|c|}
\hline \multicolumn{2}{|c|}{ Input } & \multicolumn{3}{c|}{ Output } \\
\hline $\begin{array}{c}\text { No of } \\
\text { sample } \\
\mathbf{~} \\
\text { of } \\
\text { signal } \\
\text { (N) }\end{array}$ & $\begin{array}{c}\text { Emitter } \\
\text { Locatio } \\
\mathbf{n}(\mathbf{k m})\end{array}$ & $\begin{array}{c}\text { CAF } \\
\text { Peak }\end{array}$ & $\begin{array}{c}\text { Emitter } \\
\text { Location } \\
\mathbf{( k m )}\end{array}$ & $\begin{array}{c}\text { Localisatio } \\
\mathbf{n} \text { accuracy } \\
\mathbf{( m )}\end{array}$ \\
\hline $2^{13}$ & $\begin{array}{c}(11,11,0 \\
)\end{array}$ & $7.748 \mathrm{e} 3$ & $(9.5,12.5,0)$ & 2121.32 \\
\hline $2^{14}$ & $\begin{array}{c}(11,11,0 \\
)\end{array}$ & $\begin{array}{c}20.745 \mathrm{e} \\
3\end{array}$ & $\begin{array}{c}(11.4,10.6,0 \\
)\end{array}$ & 565.7 \\
\hline $2^{16}$ & $\begin{array}{c}(11,11,0 \\
)\end{array}$ & $\begin{array}{c}67.398 \mathrm{e} \\
3\end{array}$ & $\begin{array}{c}(11.1,10.9,0 \\
)\end{array}$ & 141.4 \\
\hline
\end{tabular}

Table- III. Estimated Emitter Location under no bias in sensor kinematics at 20 snapshots

\begin{tabular}{|c|c|c|c|c|}
\hline \multicolumn{2}{|c|}{ Input } & \multicolumn{3}{c|}{ Output } \\
\hline $\begin{array}{c}\text { No of } \\
\text { sample } \\
\text { s } \\
\text { of } \\
\text { signal } \\
\text { (N) }\end{array}$ & $\begin{array}{c}\text { Input } \\
\text { Emitter } \\
\text { Locatio } \\
\mathbf{n ~ ( k m )}\end{array}$ & $\begin{array}{c}\text { CAF } \\
\text { Peak }\end{array}$ & $\begin{array}{c}\text { Output } \\
\text { Emitter } \\
\text { Location } \\
\mathbf{( k m )}\end{array}$ & $\begin{array}{c}\text { Localisatio } \\
\text { n accuracy } \\
\mathbf{( m )}\end{array}$ \\
\hline $2^{13}$ & $\begin{array}{c}(11,11,0 \\
)\end{array}$ & $\begin{array}{c}11.370 \mathrm{e} \\
3\end{array}$ & $(9.7,12.5,0)$ & 1984.94 \\
\hline $2^{14}$ & $\begin{array}{c}(11,11,0 \\
)\end{array}$ & $\begin{array}{c}31.268 \mathrm{e} \\
3\end{array}$ & $\begin{array}{c}(11.1,10.6,0 \\
)\end{array}$ & 412.31 \\
\hline $2^{16}$ & $\begin{array}{c}(11,11,0 \\
)\end{array}$ & $\begin{array}{c}122.48 \mathrm{e} \\
3\end{array}$ & $(11,10.9,0)$ & 100 \\
\hline
\end{tabular}

Table- IV. Estimated Emitter Location under no bias in sensor kinematics at 30 snapshots

\begin{tabular}{|c|c|c|c|c|}
\hline \multicolumn{2}{|c|}{ Input } & \multicolumn{3}{c|}{ Output } \\
\hline $\begin{array}{c}\text { No of } \\
\text { sample } \\
\text { s } \\
\text { of } \\
\text { signal } \\
\text { (N) }\end{array}$ & $\begin{array}{c}\text { Input } \\
\text { Emitter } \\
\text { Locatio } \\
\mathbf{n ~ ( k m )}\end{array}$ & $\begin{array}{c}\text { CAF } \\
\text { Peak }\end{array}$ & $\begin{array}{c}\text { Output } \\
\text { Emitter } \\
\text { Location } \\
\mathbf{( k m )}\end{array}$ & $\begin{array}{c}\text { Localisatio } \\
\text { n accuracy } \\
\mathbf{( m )}\end{array}$ \\
\hline $2^{13}$ & $\begin{array}{c}(11,11,0 \\
)\end{array}$ & $\begin{array}{c}13.568 \mathrm{e} \\
3\end{array}$ & $\begin{array}{c}(11.8,12.1,0 \\
)\end{array}$ & 1320.8 \\
\hline $2^{14}$ & $\begin{array}{c}(11,11,0 \\
)\end{array}$ & $\begin{array}{c}44.768 \mathrm{e} \\
3\end{array}$ & $\begin{array}{c}(11.1,10.8,0 \\
)\end{array}$ & 223.6 \\
\hline $2^{16}$ & $\begin{array}{c}(11,11,0 \\
)\end{array}$ & $\begin{array}{c}126.71 \mathrm{e} \\
3\end{array}$ & $(11,10.9,0)$ & 100 \\
\hline
\end{tabular}

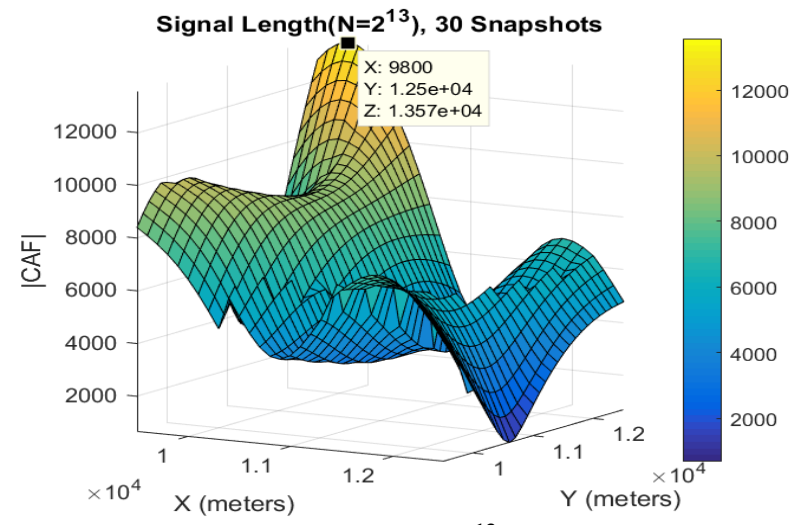

Fig. 1. CAF plot at $\mathrm{N}=2^{13}$ and 30 snapshots

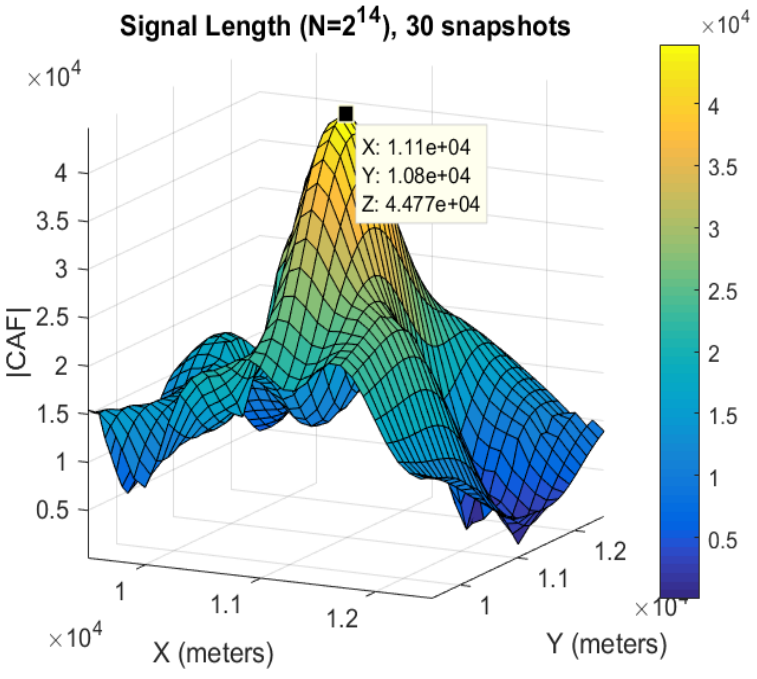

Fig. 2. CAF plot at $\mathrm{N}=2^{14}$ and 30 snapshots

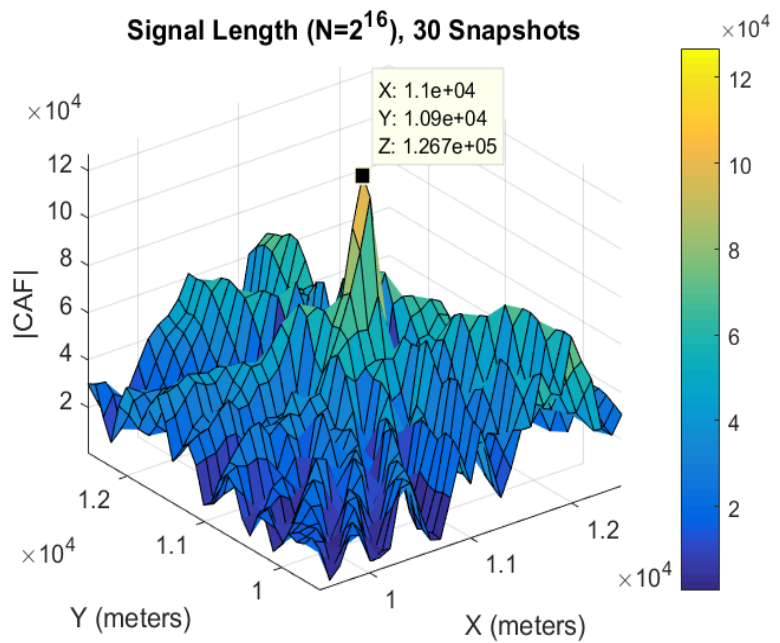

Fig. 3. CAF plot at $\mathrm{N}=2^{16}$ and 30 snapshots

\section{B. Case 2: Bias in Sensor Kinematics}

Now we will examine the effect of bias on emitter location using joint TDOA and FDOA measurements. Additive White Gaussian Noise (AWGN), with zero mean and random in nature is added to the position and velocity of the sensor. SNR is set to $30 \mathrm{~dB}$. Under biased condition, the position and velocity considered are $\mathbf{p}=\mathbf{p}^{\circ}+\Delta \mathbf{p}=\mathbf{p}^{\circ}+\sigma_{1}$ and $\dot{\mathbf{p}}=\dot{\mathbf{p}}^{\circ}+\Delta \dot{\mathbf{p}}=\dot{\mathbf{p}}^{\circ}+\sigma_{2}$, where $\sigma_{1}$ and $\sigma_{2}$ are additive white Gaussian noise in position and velocity respectively. Under this condition experiment is conducted and results are tabulated. This is shown in Table- $V$. As the maximum accuracy was obtained at 30 snapshots only, only this scenario is considered at varying number of samples. At less number of samples, TDOA and FDOA estimation error is large because there is divergence or convergence to form local minimum. Leading to less localisation accuracy. However as expected under bias conditions the proposed algorithm still achieves a fairly optimal geolocation accuracy.

Blue Eyes Intelligence Engineering 
Table- V. Comparison localisation accuracy without bias and with bias in sensor kinematics.

\begin{tabular}{|c|c|c|c|}
\hline \multirow{2}{*}{$\begin{array}{c}\text { No of } \\
\text { snap-shots }\end{array}$} & \multirow{2}{*}{$\begin{array}{c}\text { No of } \\
\text { samples of } \\
\text { signal (N) }\end{array}$} & $\begin{array}{c}\text { Localisation accuracy } \\
\text { (meters) }\end{array}$ \\
\cline { 3 - 4 } & $2^{13}$ & 1320.8 & 1513 \\
\hline \multirow{3}{*}{30} & $2^{14}$ & 223.6 & 800 \\
\cline { 2 - 4 } & $2^{16}$ & 100 & 200 \\
\cline { 2 - 4 } & \multicolumn{2}{|c}{} \\
\hline
\end{tabular}

\section{CONCLUSION}

In this paper we have proposed an algorithm for geolocating a stationary RF emitter observed that is steered by a set of moving receivers placed on high altitudes. CAF map algorithm is utilized for estimating the geolocation accuracy using joint TDOA and FDOA measurements. Using this method, the peaks obtained from the magnitude of CAF surface is directly mapped on to the geographic $x-y$ coordinates. We have simulated for geolocation accuracy by considering known sensor kinematics under no bias condition and also when there is random bias introduced in sensor position and velocity. In both the conditions, number of snapshots and signal length are varied. In simulation results it is seen that higher accuracy is obtained for larger signal collection times. At less number of samples, localization accuracy is also less. It is concluded that even if a bias exist in sensor kinematics, deviation in location accuracy is of order of few meters only. Bias cannot be ideally eliminated, but in future works attempts will be made in devising algorithms to reduce it to minimal.

\section{REFERENCES}

1. Cao, Y., Peng, L., Li, J., Yang, L., \&Guo, F. (2015). A new iterative algorithm for geolocating a known altitude target using TDOA and FDOA measurements in the presence of satellite location uncertainty. Chinese Journal of Aeronautics, 28(5), 1510-1518.

2. Kim, Y. H., Kim, D. G., \& Kim, H. N. (2015). Two-step estimator for moving-emitter geolocation using time difference of arrival/frequency-difference of arrival measurements. IET Radar, Sonar \& Navigation, 9(7), 881-887.

3. Tomic, S., Beko, M., \&Dinis, R. (2014). RSS-based localization in wireless sensor networks using convex relaxation: Noncooperative and cooperative schemes. IEEE Transactions on Vehicular Technology, 64(5), 2037-2050.

4. Vaghefi, R. M., \&Buehrer, R. M. (2014, June). Joint TOA-based sensor synchronization and localization using semidefinite programming. In 2014 IEEE International Conference on Communications (ICC) (pp. 520-525). IEEE.

5. Musicki, D., Kaune, R., \& Koch, W. (2009). Mobile emitter geolocation and tracking using TDOA and FDOA measurements. IEEE transactions on signal processing, 58(3), 1863-1874.

6. Yeredor, A., \& Angel, E. (2010). Joint TDOA and FDOA estimation: A conditional bound and its use for optimally weighted localization. IEEE Transactions on Signal Processing, 59(4), 1612-1623.

7. Stein, S. (1981). Algorithms for ambiguity function processing. IEEE Transactions on Acoustics, Speech, and Signal Processing, 29(3), 588-599.

8. Stein, S. (1993). Differential delay/Doppler ML estimation with unknown signals. IEEE Transactions on Signal Processing, 41(8), 2717-2719.

9. Ulman, R., \&Geraniotis, E. (1999). Wideband TDOA/FDOA processing using summation of short-time CAF's. IEEE transactions on signal processing, 47(12), 3193-3200.

10. Zhou, L., Zhu, W., Luo, J., \& Kong, H. (2017). Direct positioning maximum likelihood estimator using TDOA and FDOA for coherent short-pulse radar. IET Radar, Sonar \& Navigation, 11(10), 1505-1511.

Retrieval Number: C4738029320/2020@BEIESP

DOI: 10.35940/ijeat.C4738.029320

Journal Website: www.ijeat.org
11. Ho, K. C., \& Xu, W. (2004). An accurate algebraic solution for moving source location using TDOA and FDOA measurements. IEEE Transactions on Signal Processing, 52(9), 2453-2463.

12. Ho, K., \& Chan, Y. T. (1997). Geolocation of a known altitude object from TDOA and FDOA measurements. IEEE transactions on aerospace and electronic systems, 33(3), 770-783.

13. Fowler, M. L., \& Hu, X. (2008). Signal models for TDOA/FDOA estimation. IEEE Transactions on Aerospace and Electronic Systems, 44(4), 1543-1550.

14. Goh, S. S., Goodman, T. N., \& Shang, F. (2010). Joint estimation of time delay and Doppler shift for band-limited signals. IEEE Transactions on Signal Processing, 58(9), 4583-4594.

15. Youssef, M., Mah, M., \&Agrawala, A. (2007, September). Challenges: device-free passive localization for wireless environments. In Proceedings of the 13th annual ACM international conference on Mobile computing and networking (pp. 222-229). ACM.

16. Chen, M., \& Fowler, M. L. (2010). Data compression for multi-parameter estimation for emitter location. IEEE Transactions on Aerospace and Electronic Systems, 46(1), 308-322.

17. Schmidt, R. O. (1972). A new approach to geometry of range difference location. IEEE Transactions on Aerospace and Electronic Systems, (6), 821-835.

18. Ho, K. C., \& Chan, Y. T. (1993). Solution and performance analysis of geolocation by TDOA. IEEE Transactions on Aerospace and Electronic Systems, 29(4), 1311-1322.

19. Zekavat, R., \&Buehrer, R. M. (2011). Handbook of position location: Theory, practice and advances (Vol. 27). John Wiley \& Sons.

20. Zhong, X., Tay, W. P., Leng, M., Razul, S. G., \& See, C. M. S. (2016, July). Tdoa-fdoa based multiple target detection and tracking in the presence of measurement errors and biases. In 2016 IEEE 17th International Workshop on Signal Processing Advances in Wireless Communications (SPAWC) (pp. 1-6). IEEE.

21. Wang, G., Cai, S., Li, Y., \& Ansari, N. (2015). A bias-reduced nonlinear WLS method for TDOA/FDOA-based source localization. IEEE Transactions on Vehicular Technology,65(10), 8603-8615.

22. Dexiu, H. U., Huang, Z., Zhang, S., \&Jianhua, L. U. (2018). Joint TDOA, FDOA and differential Doppler rate estimation: Method and its performance analysis. Chinese Journal of Aeronautics, 31(1), 137-147.

23. Kim, D. G., Park, G. H., Kim, H. N., Park, J. O., Park, Y. M., \& Shin W. H. (2017). Computationally efficient TDOA/FDOA estimation for unknown communication signals in electronic warfare systems. IEEE Transactions on Aerospace and Electronic Systems, 54(1), 77-89.

\section{AUTHORS PROFILE}

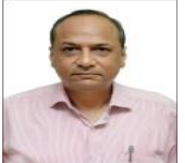

Shri Anupam Sharma, Scientist 'H' (Outstanding Scientist) did his post graduation from JK Institute of Applied Physics \& Technology, Allahabad. He joined Defence Research Development Organization in 1990 For the last 27 years, he has extensively worked in the field of Electronic Warfare at Defence Electronics Research Laboratory, Hyderabad. He is presently additional director for special projects and is also steering a Programme for high altitude EW system as Project Director. He has published several papers in many international conferences. His main research interest includes electronic warfare and statistical signal processing. He is a member of IETE, AOC and CSI.

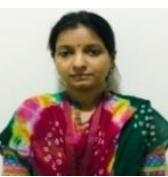

Ms. Suman Agrawal, Scientist-'E' did her B-Tech in Electronics and Communication Engineering from Rajiv Gandhi Technical University, Bhopal, MP and M.Tech in Signal Processing and Communication Networks from Indian Institute of Technology, Kanpur (IITK). For last 18 years she is working in DRDO, Hyderabad, in the field of EW. Her research interests are in statistical signal processing, wireless communication, speech communication and the development of efficien adaptive signal processing algorithms for various applications including echo cancellation and source localization. She has wide experience in working for design, development, testing and integration of several electronic warfare system/sub-systems of national importance. She is a member of IAENG, IETE and AOC.

Published By:

Blue Eyes Intelligence Engineering

\& Sciences Publication 


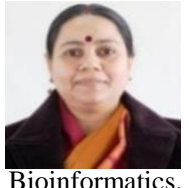

Prof. Charul Bhatnagar has more than nineteen years of teaching experience for both graduate and Post Graduate students. She has completed her $\mathrm{PhD}$ in Computer Science in the year 2007 from Banasthali Vidyapith, Rajasthan in Automata for Applications in Bioinformatics. She has supervised one PhD Thesis and more than twenty five Post Graduate Thesis. Currently she is a professor in the Department of Computer Engineering and Applications, GLA University, Mathura, India. She has published many research papers in International and National Journals and Conferences. Her main research is in the areas of Medical Image Processing, Computer Vision and Intelligent Systems. She is a Life Time Member of Computer Society of India.

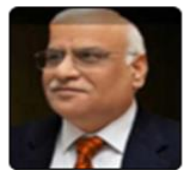

Prof. D. S. Chauhan did his B.Tech. in 1972 from IIT B.H.U. and M.Tech in 1978 from N.I.T., Tiruchirapalli. He completed his Ph.D in 1986 from IIT, Delhi. He did his post doctoral work at Goddard Space Flight Centre, Greenbelt Maryland, USA. He is presently Pro-Chancellor at GLA University, Mathura. He has published 267 research papers in International and National Journals and Conferences. He was Chairman, Advisory Committee (UGC nominee) of 4 Deemed Medical Universities and Member Board of Governors, Doon School. He is member of IEEE, AICTE, UGC, FIE, Life Member, ISTE, Member ACM, Member SIAM, Academic of International Bodies.

\section{NOMENCLATURE}

\begin{tabular}{|c|c|}
\hline B & Signal Bandwidth \\
\hline $\mathrm{f}_{\mathrm{c}}$ & Carrier frequency \\
\hline$f_{s}$ & sampling frequency \\
\hline j & Number of receivers \\
\hline$k$ & bin number \\
\hline M & Number of receivers \\
\hline$N$ & Total number of samples \\
\hline$n_{1}$ & AWGN at receiver 1 \\
\hline$n_{2}$ & AWGN at receiver 2 \\
\hline $\mathbf{p}_{1}^{\circ}$ & Initial position vector of receiver 1 \\
\hline $\mathbf{p}_{2}^{\circ}$ & Initial position vector of receiver 2 \\
\hline$\dot{\mathbf{p}}_{1}^{\circ}$ & Initial velocity vector of receiver 1 \\
\hline$\dot{\mathbf{p}}_{2}^{\circ}$ & Initial velocity vector of receiver 2 \\
\hline $\mathbf{p}^{\mathrm{e}}(\mathrm{t})$ & position vector of the emitter \\
\hline$\Delta \mathbf{p}_{\mathrm{j}}$ & Bias in the receiver $\mathrm{j}$ position \\
\hline$\Delta \dot{\mathbf{p}}_{\mathrm{j}}$ & Bias in the receiver $\mathrm{j}$ velocity \\
\hline $\mathbb{R}^{3 \times 1}$ & Real 3D space \\
\hline$s(t)$ & Signal transmitted by emitter \\
\hline $\mathrm{s}_{1}(\mathrm{t})$ & Signal received by sensor 1 \\
\hline $\mathrm{S}_{2}(\mathrm{t})$ & Signal received by sensor 2 \\
\hline $\mathrm{T}$ & matrix transpose \\
\hline$T_{s}$ & sampling period \\
\hline$x_{t}^{0}, y_{t}^{0}, z_{t}^{0}$ & Initial coordinates of receiver \\
\hline $\mathrm{x}_{\mathrm{t}}^{\mathrm{e}}, \mathrm{y}_{\mathrm{t}}^{\mathrm{e}}, \mathrm{z}_{\mathrm{t}}^{\mathrm{e}}$ & coordinates of emitter \\
\hline$v$ & Doppler Shift \\
\hline $\boldsymbol{\beta}^{\circ}$ & $\begin{array}{l}\text { Initial vector of AWGN without bias in position } \\
\text { city }\end{array}$ \\
\hline$\beta$ & $\begin{array}{l}\text { Vector of AWGN without bias in position and } \\
\text { velocity }\end{array}$ \\
\hline$\Delta \beta$ & $\begin{array}{l}\text { Vector of AWGN with bias in position and } \\
\text { velocity }\end{array}$ \\
\hline & Shift in the signal \\
\hline
\end{tabular}

Time delay

Maximum Time Delay

Maximum frequency

Random bias at receiver 1

Random bias at receiver 2 